\title{
General anesthesia affecting on developing brain: evidence from animal to clinical research
}

\author{
Xinyue Liu $^{1}$. . Jing $\mathrm{Ji}^{1}$ - Guo-Qing Zhao ${ }^{1}$
}

Received: 31 December 2019 / Accepted: 6 June 2020 / Published online: 29 June 2020

(c) The Author(s) 2020

\begin{abstract}
As the recent update of General anaesthesia compared to spinal anaesthesia (GAS) studies has been published in 2019, together with other clinical evidence, the human studies provided an overwhelming mixed evidence of an association between anaesthesia exposure in early childhood and later neurodevelopment changes in children. Pre-clinical studies in animals provided strong evidence on how anaesthetic and sedative agents (ASAs) causing neurotoxicity in developing brain and deficits in long-term cognitive functions. However pre-clinical results cannot translate to clinical practice directly. Three well designed large population-based human studies strongly indicated that a single brief exposure to general anesthesia (GAs) is not associated with any long-term neurodevelopment deficits in children's brain. Multiple exposure might cause decrease in processing speed and motor skills of children. However, the association between GAs and neurodevelopment in children is still inconclusive. More clinical studies with larger scale observations, randomized trials with longer duration exposure of GAs and follow-ups, more sensitive outcome measurements, and strict confounder controls are needed in the future to provide more conclusive and informative data. New research area has been developed to contribute in finding solutions for clinical practice as attenuating the neurotoxic effect of ASAs. Xenon and Dexmedetomidine are already used in clinical setting as neuroprotection and anaesthetic sparing-effect, but more research is still needed.
\end{abstract}

Keywords General anaesthesia $\cdot$ Pre-clinical study $\cdot$ Clinical study $\cdot$ Randomized trial $\cdot$ Neurotoxicity $\cdot$ Cognitive deficit

$\begin{array}{ll}\text { Abbreviations } \\ \text { GAs } & \text { General anaesthesia } \\ \text { GABA } & \gamma \text {-Aminobutyric acid } \\ \text { NMDA } & N \text {-Methyl-D-asparate } \\ \text { CNS } & \text { Central nerve system } \\ \text { FDA } & \text { US Food and Drug Administration } \\ \text { NGF } & \text { Nerve growth factor } \\ \text { TNF } & \text { Tumour necrosis factor } \\ \text { ROS } & \text { Reactive oxygen species } \\ \text { PANDA } & \begin{array}{l}\text { Pediatric Anaesthesia Neurodevelopment } \\ \text { Assessment }\end{array} \\ \text { GAS } & \begin{array}{l}\text { General anaesthesia compared to spinal } \\ \text { anaesthesia }\end{array} \\ \text { MASK } & \text { Mayo Anesthesia Safety in Kids } \\ \text { FSIQ } & \text { Full-scale intelligence quotient } \\ \text { IQ } & \text { Cognitive function } \\ \text { OTB } & \text { Operant Test Battery }\end{array}$

Guo-Qing Zhao

guoqingzhao1965@163.com

1 Department of Anesthesiology, China-Japan Union Hospital of Jilin University, Changchun, China

\begin{abstract}
PPP Public-private partnership
ASAs Anaesthetic and sedative agents
\end{abstract}

\section{Introduction}

The advent of the modern general anaesthesia (GAs) made it possible for the advancement of modern complex surgical and diagnostic procedures in seriously ill patients of all age groups. Anaesthetic and sedative reagents affect the central nervous system (CNS) by interacting with neurotransmitters and resolving neuronal integration between different brain regions. Presently widely used anesthetics act by two major mechanisms, (1) increasing inhibition through $\gamma$-aminobutyric acid (GABA) receptors (e.g., benzodiazepines, barbiturates, propofol, etomidate, isoflurane, enflurane, and halothane) [1] and 2) decreasing the excitation via $\mathrm{N}$-methyl-D-asparate (NMDA) receptors [e.g., ketamine, nitrous oxide $\left(\mathrm{N}_{2} \mathrm{O}\right)$, and xenon] [2].

In the last 20 years, more and more evidence from animal studies, including non-human primates, have indicated the potentials for GAs agents to cause neuro-apoptosis and other 
neurodegenerative changes in the developing mammalian brain. It has been demonstrated that exposure to GAs, predominately during the early postnatal period triggers longterm morphological and functional changes in the CNS, which in turn can result in impairment of neurocognitive performance [3]. It arouse the concerns about anaesthesia related neurological injury in young children among parents, health-care providers and regulatory authorities. Several human clinical studies including different outcome measurements interpreted the associations between surgery in early childhood and slightly worse subsequent academic performance or increased risk of the behavioral abnormity. In 2016, the US Food and Drug Administration (FDA) issued a safety announcement, warning that "repeated or lengthy use of general anesthetic and sedation drugs during surgeries or procedures in children younger than 3 years or in pregnant women during their third trimester may affect the development of children's brains" [4]. And in 2017, FDA issued a change in labeling regarding the safe use of anaesthetic and sedative reagents [5].

As more and more clinical evidence has been revealed about how anaesthetic and sedative reagents affect development of human brain, it is more important to analyze the strengths and limitations of all the clinical evidence in order to determine the changes in clinical practice. This review will be focusing on the new findings in both pre-clinical research and clinical studies, with the brief summarization of the animal studies and current clinical evidence that have been well reported. Finally, the future and ongoing clinical studies will be discussed as the future directions for anaesthetic research on developing brain.

\section{Pre-clinical evidence: early-life anaesthesia exposure}

The initial pre-clinical studies of anaesthesia induced developmental neurotoxicity were done with rodent models. Rodent brains undergo brain growth spurt period (synaptogenesis) mainly at postnatal time. The brain maturation reaches $90-95 \%$ of adult weight for fairly short time (postnatal day 20-21). And the key developmental processes, like synaptogenesis, blood-brain barrier establishment and oligodendrocyte maturation etc., across ages are well defined $[6,7]$. During normal synaptogenesis, neurons that fail to develop synaptic contact will undergo programmed cell death also known as apoptosis. As for neuronal development, migration, differentiation and synaptogenesis, two of the major factors that influence all are excitatory and inhibitory neurotransmitters. The most important excitatory neurotransmitter that mainly contribute to neurogenesis is glutamate, which acts mainly by activating the NMDA receptor. The most important inhibitory neurotransmitter in mature brain is GABA. In the immature brain, the GABA receptor is excitatory, and its activation leads to a depolarization in the immature neuron. During development, the intracellular chloride concentration decreases, and the GABA receptor is transitioning from being excitatory to inhibitory receptor in the adult brain. Other important factors that involves in neurogenesis are growth factors, like nerve growth factor (NGF) and brain-derived neurotrophic factor (BDNF). These factors mainly regulate the differentiation of progenitor cells, axoand dendrite-genesis, as well as neuronal cell survival [8].

As known that all commonly used anesthetic and sedative reagents provide anaesthetic and sedative effects by binding to the GABA receptor, or the NMDA receptor, or both. The first animal study by Jevtovic-Todorovic et al., demonstrated that routine GAs (isoflurane, sevoflurane, propofol, ketamine) are capable of producing lasting cognitive, behavioral and memory deficiency in postnatal day 7 rats when exposed with $6 \mathrm{~h}$ mixture of nitro oxide, isoflurane and midazolam [2]. More cellular and animal studies have provided substantial and convincing evidence on the cytotoxic and neurotoxic effects of GAs. Furthermore, studies on non-human primates aligned with the results in rodents research, finding that early-life exposure to ketamine, sevoflurane or isoflurane can lead to persistent decline in cognitive, executive, memory and motivation-based tasks, and increase anxiety behaviours in long term [9-11].

The molecular mechanisms of cytotoxic and neurotoxic effect of general anaesthetics on developing brain have been extensively explored. In-vitro and in-vivo studies have revealed that anaesthetics induce apoptosis via two possible pathways: intrinsic pathway and extrinsic pathway [12]. The extrinsic pathway is activated via tumour necrosis factor (TNF) receptors. While the intrinsic pathway is initiated in response to signals from within the cell, this results in the decreasing anti-apoptotic BCL-2/pro-apoptotic Bax ratio, increasing reactive oxygen species (ROS), and promoting cytochrome $\mathrm{C}$ to be released from the mitochondria and activating caspase- 3 cleavage. GAs accelerates the process of apoptosis during the period when GABA receptor is excitatory. While applying the GAs at a later neuronal development stage when GABA receptor is inhibitory, it induces less neurodegeneration. However, the negative effects on learning and memory are still exist. Both long-term blockage of excitatory and the activation of inhibitory receptors, neuronal synapses may induce a change in receptor expression. This might influence the excitability of the neuron and make it more vulnerable to toxic stimuli. For neuronal development, both excitatory and inhibitory input from adjacent neurons are essential. By blocking the connection from adjacent neurons, the differentiation and survival might be critically affected. Other studies also suggested that GAs causes deficit in axon myelination by affecting glial cells [13]. Recently anaesthetic-induced neuroinflammation has 
been revealed as a possible mechanism for cognitive impairment in immature mice [14].

The current available animal studies give rises to several important indications of factors that affect toxicity of earlylife anaesthesia on animals. First is the developmental stage at which animals are exposed to GAs. Neuronal cells tend to be more vulnerable during the brain growth spurt period. And the timing of this period varies from species, in rat, it lasts from the 7 th up to 17 th postnatal day and in rhesus monkeys from the 5th to the 16th postnatal day [6]. The peak period of synaptogenesis various between brain regions and different neuronal cell types [15]. Different neuronal cell types may possess different susceptibility to GAs. Glutaminergic and GABAergic neurons may be more vulnerable to toxic effects than cholinergic neurons [16].

Second important factor is the length and frequency of exposure to the general anaesthetics. Neurocognitive deficits have been identified after several hours GAs administration but not after short-term single administration of GAs [17]. Repeated, short-time exposures to the GAs also results in cognitive dysfunction, indicating that accumulative length of exposure to GAs within a certain period of time is one of key factors $[14,18]$.

Third, a dose-dependent toxicity effect has been revealed in animal studies. Higher the dose of GAs is, the larger the number of apoptotic neurons is. The dosage of GAs can affect the degree of developmental impairment, cell differentiation and synaptogenesis [1, 19].

Lastly, recent studies suggest that the sensitivity to GAs may vary between sexes. One study in rats showed males and females followed distinct paths of neural and cognitive development after an early anesthetic-mediated effect on the brain. Both male and female rats exhibited extensive neuronal death. However drastic behavioral impairment was manifested only in male subjects [20].

\section{The gap and limitation of the findings from animal studies transferring to clinical practice}

Researchers have focused substantial attention to evaluating the development of cognitive abilities of animals exposed to GAs at the peak of synaptogenesis. It has been concluded that GAs exposure animals showed abnormality in memory and cognitive in adulthood comparing with GAs nonexposure animals. Both single long exposure and repeatedly, short-term exposure to GAs during critical stage of brain development can cause significant impairments in neurocognitive development. We know that the critical stages of brain development various from species. Then how to imply the findings from animal research to clinical practice?
In human brain, the synaptogenesis period is thought to last from the last trimester until the third year of life which is way longer comparing to rodent and rhesus monkeys. It is hard to imply the critical development stages that mostly affected by GAs directly from animal studies [21]. Besides, the animal studies basically used healthy animals to expose to GAs. In the clinical situation, it is often with children in need of surgery, whom might be exposed to prolonged surgeries and have multiple postoperative complications, like pain, anxiety, fluid imbalance, and surgery-induced trauma [22]. There are only limited animal studies including surgical or pain stimuli into consideration, but the results are contradictory. One study published in 2012 by Shu et al., showed that rat pups who received GAs for $6 \mathrm{~h}$ with a hind paw incision or formalin injection respectively, exhibited higher degree of neuro-apoptosis in brain cortex and spinal cord. These subjects also showed long-term impairments comparing to age-matched animals which have been exposed to GAs alone without nociceptive stimulus [23]. Interestingly another study published in the same year by Liu et al., suggested that $6 \mathrm{~h}$ exposure of rat pups to GAs with chemical nociception induced by complete Freund's adjuvant resulted in attenuated anaesthesia-induced neuro-apoptotic response. Cognitive behavior in later life was not assessed [24]. All these indicating that the real situation in clinical setting is way more complicated. It would be challenging to establish a clear relevance of the animal studies to clinical practice. However pre-clinical animal studies are still valuable as they revealed the molecular and cellular mechanism for GAs toxicity in developing brain [25]. The behavior and pathological data from animal studies can provide reference for the designing clinical studies.

\section{Clinical evidence: what we can imply from all the clinical data and what's next}

The first reported study in 1953 by Eckenhoff et al., suggested possible relevance between personality change and pre-anaesthetic medication (pentobarbital, scopolamine and morphine) [26]. However no clear link between surgery and neurodevelopmental outcome had been noticed outside the neonatal period. There was no obvious clinical problem, until the preclinical data has grown. There was an increasing urge to find out if GAs exposure does indeed cause the clinical relevance of neurodevelopment dysfunction in children. The answer to this question is not easy or straightforward. There are many aspects and concerns needed to be taken into consideration, regarding the GAs effects on children. The effect might be dependent on the choice of anaesthetics. The GAs approach varies based on the child's age, medical/surgical history, types of surgical procedure and duration of anaesthesia administration and the nature of the anaesthesia exposure. Unfortunately, translation 
pre-clinical data in human is imprecise and inapplicable. A recent review by integrating more than 440 pre-clinical studies with exceed 30 clinical studies up to date, demonstrated no clear exposure duration threshold below which no structural injury or subsequent cognitive abnormalities occurred. Animal data did not clearly identify a specific age beyond which anaesthetic exposure did not cause any structural or functional abnormalities [27]. All these make it even harder for human studies to use pre-clinical data as a guideline to design clinical research.

Given the uncertainty of translating the pre-clinical data, it is impossible to design a single randomized controlled human study including all the affecting factors to determine the outcomes. It is more appropriate for a range of studies to examine a range of outcomes, anaesthetic duration and age at exposure. Many elaborate reviews on this topic have been published recently and assessed most of the clinical studies [3, 28-31]. In this review, we will briefly summarize the upto-date and the most well designed three clinical studies and discuss the limitations. Most importantly, we will discuss the implications from human studies that can guide the clinical practice and future directions for designing clinical research.

\section{The Pediatric Anaesthesia Neurodevelopment Assessment (PANDA) Study}

PANDA study used a sibling-matched cohort design to test if a single anaesthesia exposure in healthy young children is associated with impaired neurocognitive development and abnormal behavior in later children. The study cohort included sibling pairs within 36 months in age and currently 8-15 years old. All exposed children received inhaled anaesthetic agents and anaesthesia median duration of $80 \mathrm{~min}$. 105 sibling pairs were included in the primary outcome, global cognitive function (IQ) test. There was no statistically significantly differences in mean scores between exposed siblings and unexposed siblings. A detailed neuropsychological battery assessed IQ and domain-specific neurocognitive functions as the secondary outcomes also showed no statistically significant differences between sibling pairs in memory/learning, motor/processing speed, visuospatial function, attention, executive function, language, or behavior [32].

\section{The general anaesthesia compared to spinal anaesthesia (GAS) study}

The first randomised trial was designed as GAS consortium to verify whether anaesthesia exposure in early childhood can cause long-term neurodevelopment changes. Two established anaesthetic techniques for inguinal herniorrhaphy treating postoperative apnea in young infant: awakeregional and sevoflurane-based Gas [33]. Between the year 2007-2013, 722 infants up to 60 weeks who were recruited in the trial from 28 hospitals in multiple countries were randomly assigned to receive either awake-regional or sevoflurane-based GAs for inguinal herniorrhaphy. The median duration of anaesthesia in the GAs group was $54 \mathrm{~min}$. The outcomes of neurodevelopment were assessed at 2 years of age and 5 years of age respectively. The secondary outcome, the composite cognitive score of the Bayley Scales of Infant and Toddler Development III, assessed at 2 years of age and published in 2016, providing strong evidence for equivalence between awake-regional anaesthesia and GAs in infancy in terms of neurodevelopment [34]. The primary outcome measure was full-scale intelligence quotient (FSIQ) on the Wechsler Preschool and Primary Scale of Intelligence, third edition at 5 years of age published recently in 2019. The results were interpreted that slightly less than $1 \mathrm{~h}$ of GAs in early infancy does not alter neurodevelopmental outcome at 5 years of age compared with awake-regional anaesthesia in a predominantly male study population [35].

\section{Mayo Anesthesia Safety in Kids (MASK) study}

MASK study enrolled children born in Olmsted County, Minnesota, USA, from 1994 to 2007, who were exposed to surgery and anaesthesia before the age of 3 year. Total 997 children were enrolled in the MASK study. 380 children had a single exposure to GAs, 206 children had multiple exposure to GAs, and 411 were unexposed. Enrolled children were sampled using a propensity-guided approach and underwent neuropsychological testing at age 8-12 or 15-20 year. The primary outcome based on the Full-Scale intelligence quotient standard score of the Wechsler Abbreviated Scale of Intelligence did not differ significantly according to exposure status. Secondary assessment including individual domains from a comprehensive neuropsychological assessment and parent reports, found that processing speed and fine motor abilities were decreased in the multiple but not the single exposed children. Other functions did not show significant difference accordingly. The parents of multiple exposed children reported increased problems related to executive function, behaviour, and reading [36, 37].

Two follow-up studies of MASK study attempted to translate the non-human primate data to humans and perform additional analysis to verify the results [38, 39]. One follow-up study done by Warner et al., proposed reasons for the variability in the results of anaesthetics clinical neurotoxicity. As with neurotoxic exposure, not all cognitive domains might be equally affected and specific domains that are affected by GAs are still not clear. By applying the 
knowledge from animal studies, Warner and colleagues picked the neurodevelopment test, Operant Test Battery (OTB) which can be used both in humans and animals. There was no difference found in OTB scores even after multiple exposure in children. However, previous nonhuman primate studies showed decrease in OTB accuracy and response speed after anaesthetic exposure [11]. The difference of the findings might be due to the insensitivity of OTB test for detecting small effects in children. Also the median anaesthetic exposure duration for children in MASK study was $45 \mathrm{~min}$ for single exposure and $187 \mathrm{~min}$ for multiple exposure [36], while the non-human primate study used a $24 \mathrm{~h}$ infusion of ketamine, which is not only a very long exposure but also an anaesthetic drug that is not the choice in most paediatric procedures [11]. This MASK study finding is consistent with other published studies showing that anaesthetic exposure does not result in large cognitive deficits, particularly in domains associated with intelligence.

The other MASK follow-up study done by Zaccariello et al., preformed a secondary re-analysis of some of the neuropsychologist-assessed outcomes presented in the initial MASK study [36]. Two analyses, a factor and a cluster analysis were performed in this follow-up study. The results showed that children with multiple exposures had lower scores in processing speed, motor coordination and visualmotor integration, but no differences were seen in the children after a single exposure [39].

GAS and PANDA studies provided strong evidence that infants exposing to a single brief (less than $1 \mathrm{~h}$ ) GAs does not cause significant neurocognitive or behavioural deficits. The MASK study also verified the same conclusion. Besides, MASK study provided evidence that not the single exposure but the multiple exposure to GAs in young children is associated with a specific pattern of deficits. However, this is just the beginning of understanding how GAs affects neurodevelopment in infants. The current published clinical studies have limitations to address the issue thoroughly and there are still missing puzzles.

First of all, the dosage dependent effect of GAs is still not clear. GAS and PANDA studies all used less than $1 \mathrm{~h}$ brief anaesthetic exposure showing no effect in long-term neurodevelopment. MASK studies indicated that single average 45 min exposure does not affect gross neurodevelopment, while multiple exposure with average of $187 \mathrm{~min}$ period caused the deficits in fine motor skills. Current results do not provide data regarding to the neurocognitive risks of repeated episodes of anesthesia exposure or more prolonged durations of a single exposure which often happen in complicated pediatric surgeries.

Secondly, the current cognitive and behavioral tests used for clinical studies are not sensitive enough to analysis in depth how affected sub-domains in the brain are. Like the Bayley III assessment method used in GAS studies is a well validated assessment for current neurodevelopment and early neurobehavioral assessment of children. However, it is not a perfect predictor for long-term outcome. Further analysis of the data collected from current clinical studies could also provide more information and evidence [40].

Thirdly, the GAs effect on different sex has not been fully addressed in the PANDA and GAS study. Pre-clinical data indicated that anaesthetic drugs might affect long-term cognitive function differently between sexes [20]. Only MASK studies females and males were equally recruited in the studies, but not separately analyzed. In PANDA and GAS studies, the majority of the recruited children were males [27].

Last but not least, all three studies were assessed the association between surgery plus anesthetic exposure and cognitive/behavior deficiency. It is hard to rule out the impact of the surgery contribution to the outcomes. Furthermore, confounders such as hypotension, body temperature, and hypoxia during surgery are rarely included in these studies. These confounders could potentially alter the outcomes [30].

\section{Discussions and conclusions}

In pre-clinical studies, adverse neurological effects of commonly used anaesthetic agents are seen in rodents and nonhuman primates. Long duration, repeated exposure and multiple agents can increase neurotoxicity, cognitive and behavioral function. Due to the difference in brain development between human and other animals, the results of the pre-clinical studies cannot directly apply to clinical practice. SmartTots, a public-private partnership (PPP) was established between the FDA and the International Anesthesia Research Society (IARS) in 2009, to facilitate pediatric anesthesia research with aim of making surgery safer for infants and children [41, 42]. Multiple published epidemiologic studies assessed the association between GAs exposure in early life and neurodevelopment in later life of children. Due to the limitation of the sample size and lack of sensitivity of the measurements, the results showed various outcomes and some contradictories [29, 43-45]. Three well-designed clinical studies discussed in this review found evidence showing that not a single brief exposure but multiple exposure to GAs in children within 3 years age decreased processing speed and motor skills. The difference was not found in other cognitive functions [32, 34-36, 46]. One of the MASK follow-up studies provided more information and possible future directions for further designing clinical studies. The results showed that anaesthetic exposure, even multiple exposure, did not result in gross deficits in all exposed children. This indicates that the effects of GAs on children are likely to be subtle and not all children are universally vulnerable [39]. As there are important limitations in the published observational studies, it is still not sufficient 
in evidence to conclude that GAs directly has any long-term impact in children [47]. Besides more clinical studies with larger scale observation in need for sequential clinical studies. Randomized trials with longer duration exposure of GAs, follow-ups, more sensitive outcome measurements, and strict confounder controls should also be included to provide more conclusive and informative data. Meanwhile, new research area has been developed in order to find possible solutions that can attenuate anaesthetics neurotoxicity effect on developing brain. Different drugs are being studied to mitigate the apoptosis response to ASAs. Xenon and Dexmedetomidine (DEX) are already used in clinical settings as neuroprotection and anaesthetic sparing-effect, but more research is still needed [48-51].

Evidence from clinical studies on association between GAs and neurodevelopment provided more information for clinical practice. While, at this point it is still inconclusive. Thus, changes in clinical management of children are not advised at this time. It is less important than the benefit of medical procedure has done for the children. However, in order to allow parents and healthcare providers to make informed clinical decision, the risk of anaesthesia should be adequately and fully evaluated.

Acknowledgements No external funding or competing interest declared.

Author contributions XL as the primary author contributed in drafting and editing the manuscript. $\mathrm{JJ}$ as the secondary author participated in editing the manuscript. G-QZ as the correspondence supervised and reviewed and edited the manuscript.

Open Access This article is licensed under a Creative Commons Attribution 4.0 International License, which permits use, sharing, adaptation, distribution and reproduction in any medium or format, as long as you give appropriate credit to the original author(s) and the source, provide a link to the Creative Commons licence, and indicate if changes were made. The images or other third party material in this article are included in the article's Creative Commons licence, unless indicated otherwise in a credit line to the material. If material is not included in the article's Creative Commons licence and your intended use is not permitted by statutory regulation or exceeds the permitted use, you will need to obtain permission directly from the copyright holder. To view a copy of this licence, visit http://creativecommons.org/licenses/by/4.0/.

\section{References}

1. Vutskits L, Gascon E, Tassonyi E, Kiss JZ. Clinically relevant concentrations of propofol but not midazolam alter in vitro dendritic development of isolated $\gamma$-aminobutyric acid-positive interneurons. Anesthesiology. 2005;102(5):970-6. https://doi. org/10.1097/00000542-200505000-00016.

2. Jevtovic-Todorovic V, Hartman RE, Izumi Y, Benshoff ND, Dikranian K, Zorumski CF, Olney JW, Wozniak DF. Early exposure to common anesthetic agents causes widespread neurodegeneration in the developing rat brain and persistent learning deficits. J Neurosci. 2003;23(3):876-2.
3. Sinner B, Becke K, Engelhard K. General anaesthetics and the developing brain: an overview. Anaesthesia. 2014;69(9):1009_ 222. https://doi.org/10.1111/anae.12637.

4. US Food and Drug Administration. Drug Safety and Availability-FDA Drug Safety Communication: FDA Review Results in New Warnings about Using General Anesthetics and Sedation Drugs in Young Children and Pregnant Women. 2016. https:// www.fda.gov/Drugs/DrugSafety/ucm532356.htm. Accessed 20 Dec 2019.

5. US Food and Drug Administration. FDA Drug Safety Communication: FDA Approves Label Changes for Use of General Anesthetic and Sedation Drugs in Young Children. 2017. https:// www.fda.gov/Drugs/DrugSafety/ucm554634.htm. Accessed 20 Dec 2019.

6. Semple BD, Blomgren K, Gimlin K, Ferriero DM, NobleHaeusslein LJ. Brain development in rodents and humans: identifying benchmarks of maturation and vulnerability to injury across species. Prog Neurobiol. 2013;106-107:1-16. https://doi. org/10.1016/j.pneurobio.2013.04.001.

7. Workman AD, Charvet CJ, Clancy B, Darlington RB, Finlay BL. Modeling transformations of neurodevelopmental sequences across mammalian species. J Neurosci. 2013;33(17):7368-83. https://doi.org/10.1523/jneurosci.5746-12.2013.

8. Lu LX, Yon JH, Carter LB, Jevtovic-Todorovic V. General anesthesia activates BDNF-dependent neuroapoptosis in the developing rat brain. Apoptosis. 2006;11(9):1603-15. https://doi. org/10.1007/s10495-006-8762-3.

9. Slikker W Jr, Zou X, Hotchkiss CE, Divine RL, Sadovova N, Twaddle NC, Doerge DR, Scallet AC, Patterson TA, Hanig JP, Paule MG, Wang C. Ketamine-induced neuronal cell death in the perinatal rhesus monkey. Toxicol Sci. 2007;98(1):145-58. https ://doi.org/10.1093/toxsci/kfm084.

10. Brambrink AM, Evers AS, Avidan MS, Farber NB, Smith DJ, Martin LD, Dissen GA, Creeley CE, Olney JW. Ketamine-induced neuroapoptosis in the fetal and neonatal rhesus macaque brain. Anesthesiology. 2012;116(2):372-84. https://doi.org/10.1097/ aln.0b013e318242b2cd.ketamine-induced.

11. Paule MG, Li M, Allen RR, Liu F, Zou X, Hotchkiss C, Hanig JP, Patterson TA, Slikker W Jr, Wang C. Ketamine anesthesia during the first week of life can cause long-lasting cognitive deficits in rhesus monkeys. Neurotoxicol Teratol. 2011;33(2):220-30. https ://doi.org/10.1016/j.ntt.2011.01.001.

12. Yon JH, Daniel-Johnson J, Carter LB, Jevtovic-Todorovic V. Anesthesia induces neuronal cell death in the developing rat brain via the intrinsic and extrinsic apoptotic pathways. Neuroscience. 2005;135(3):815-27. https://doi.org/10.1016/j.neuroscien ce.2005.03.064.

13. Creeley C, Dikranian K, Dissen G, Martin L, Olney J, Brambrink A. Propofol-induced apoptosis of neurones and oligodendrocytes in fetal and neonatal rhesus macaque brain. Br J Anaesth. 2013;110(suppl 1):i29-i38. https://doi.org/10.1093/bja/aet173.

14. Shen X, Dong Y, Xu Z, Wang H, Miao C, Soriano SG, Sun D, Baxter MG, Zhang Y, Xie Z. Selective anesthesia-induced neuroinflammation in developing mouse brain and cognitive impairment. Anesthesiology. 2013;118(3):502-15. https://doi. org/10.1097/aln.0b013e3182834d77.

15. Hofacer RD, Deng M, Ward CG, Joseph B, Hughes EA, Jiang C, Danzer SC, Loepke AW. Cell age-specific vulnerability of neurons to anesthetic toxicity. Ann Neurol. 2013;73(6):695-704. https:// doi.org/10.1002/ana.23892.

16. Zhou ZW, Shu Y, Li M, Guo X, Pac-Soo C, Maze M, Ma D. The glutaminergic, GABAergic, dopaminergic but not cholinergic neurons are susceptible to anaesthesia-induced cell death in the rat developing brain. Neuroscience. 2011;174:64-70. https://doi. org/10.1016/j.neuroscience.2010.10.009. 
17. Qiu L, Zhu C, Bodogan T, Gómez-Galán M, Zhang Y, Zhou K, Li $\mathrm{T}, \mathrm{Xu}$ G, Blomgren K, Eriksson LI, Vutskits L, Terrando N. Acute and long-term effects of brief sevoflurane anesthesia during the early postnatal period in rats. Toxicol Sci. 2016;149(1):121-33. https://doi.org/10.1093/toxsci/kfv219.

18. Raper J, Alvarado MC, Murphy KL, Baxter MG. Multiple anesthetic exposure in infant monkeys alters emotional reactivity to an acute stressor. Anesthesiology. 2015;123(5):1084-92. https:// doi.org/10.1097/ALN.0000000000000851.

19. Sinner B, Friedrich O, Zink W, Zausig Y, Graf BM. The toxic effects of $\mathrm{s}(+)$-ketamine on differentiating neurons in vitro as a consequence of suppressed neuronal $\mathrm{Ca} 2+$ oscillations. Anesth Analg. 2011;113(5):1161-9. https://doi.org/10.1213/ANE.0b013 e31822747df.

20. Lee BH, Chan JT, Kraeva E, Peterson K, Sall JW. Isoflurane exposure in newborn rats induces long-term cognitive dysfunction in males but not females. Neuropharmacology. 2014;83:9-17. https ://doi.org/10.1016/j.neuropharm.2014.03.011.

21. Rappaport BA, Suresh S, Hertz S, Evers AS, Orser BA. Anesthetic neurotoxicity - clinical implications of animal models. N Engl J Med. 2015;372(9):796-7. https://doi.org/10.1056/nejmp1414786.

22. Brummelte S, Grunau RE, Chau V, Poskitt KJ, Brant R, Vinall J, Gover A, Synnes AR, Miller SP. Procedural pain and brain development in premature newborns. Ann Neurol. 2012;71(3):385-96. https://doi.org/10.1002/ana.22267.

23. Shu Y, Zhou Z, Wan Y, Sanders RD, Li M, Pac-Soo CK, Maze M, Ma D. Nociceptive stimuli enhance anesthetic-induced neuroapoptosis in the rat developing brain. Neurobiol Dis. 2012;45(2):743-50. https://doi.org/10.1016/j.nbd.2011.10.021.

24. Liu JR, Liu Q, Li J, Baek C, Han XH, Athiraman U, Soriano SG. Noxious stimulation attenuates ketamine-induced neuroapoptosis in the developing rat brain. Anesthesiology. 2012;117(1):64-71. https://doi.org/10.1097/ALN.0b013e31825ae693.

25. Vutskits L, Xie Z. Lasting impact of general anaesthesia on the brain: mechanisms and relevance. Nat Rev Neurosci. 2016;17(11):705-17. https://doi.org/10.1038/nrn.2016.128.

26. Eckenhoff JE. Relationship of anesthesia to postoperative personality changes in children. AMA Am J Dis Child. 1953;86(5):58791. https://doi.org/10.1001/archpedi.1953.02050080600004.

27. Warner DO, Flick RP. Anaesthetics, infants, and neurodevelopment: case closed? Lancet. 2016;387(10015):202-4. https://doi. org/10.1016/S0140-6736(15)00669-8.

28. Andropoulos DB. Effect of anesthesia on the developing brain: Infant and fetus. Fetal Diagn Ther. 2018;43(1):1-11. https://doi. org/10.1159/000475928.

29. Davidson AJ, Sun LS. Clinical evidence for any effect of anesthesia on the developing brain. Anesthesiology. 2018;128(4):840-53.

30. Wu L, Zhao H, Weng H, Ma D. Lasting effects of general anesthetics on the brain in the young and elderly: "mixed picture" of neurotoxicity, neuroprotection and cognitive impairment. J Anesth. 2019;33(2):321-35. https://doi.org/10.1007/s00540-01902623-7.

31. Lin EP, Lee JR, Lee CS, Deng M, Loepke AW. Do anesthetics harm the developing human brain? An integrative analysis of animal and human studies. Neurotoxicol Teratol. 2017;60:117-28. https://doi.org/10.1016/j.ntt.2016.10.008.

32. Sun LS, Li G, Miller TLK, Salorio C, Byrne MW, Bellinger DC, Ing C, Park R, Radcliffe J, Hays SR, DiMaggio CJ, Cooper TJ, Rauh V, Maxwell LG, Youn A, McGowan FX. Association between a single general anesthesia exposure before age 36 months and neurocognitive outcomes in later childhood. JAMA J Am Med Assoc. 2016;315(21):2312-20, https://doi.org/10.1001/ jama.2016.6967.

33. Davidson AJ, Morton NS, Arnup SJ, de Graaff JC, Disma N, Withington DE, Frawley G, Hunt RW, Hardy P, Khotcholava M, von Ungern Sternberg BS, Wilton N, Tuo P, Salvo I, Ormond
G, Stargatt R, Locatelli BG, McCann ME. Apnea after awake regional and general anesthesia in infants. Anesthesiology. 2015;123(1):38-54. https://doi.org/10.1097/aln.0000000000 000709 .

34. Davidson AJ, Disma N, de Graaff JC, Withington DE, Dorris L, Bell G, Stargatt R, Bellinger DC, Schuster T, Arnup SJ, Hardy P, Hunt RW, Takagi MJ, Giribaldi G, Hartmann PL, Salvo I, Morton NS, von Ungern Sternberg BS, Locatelli BG, Wilton N, Lynn A, Thomas JJ, Polaner D, Bagshaw O, Szmuk P, Absalom AR, Frawley G, Berde C, Ormond GD, Marmor J, McCann ME. Neurodevelopmental outcome at 2 years of age after general anaesthesia and awake-regional anaesthesia in infancy (GAS): an international multicentre, randomised controlled trial. Lancet. 2016;387(10015):239-50. https://doi.org/10.1016/S0140 $-6736(15) 00608-X$.

35. McCann ME, de Graaff JC, Dorris L, Disma N, Withington D, Bell G, Grobler A, Stargatt R, Hunt RW, Sheppard SJ, Marmor J, Giribaldi G, Bellinger DC, Hartmann PL, Hardy P, Frawley G, Izzo F, von Ungern Sternberg BS, Lynn A, Wilton N, Mueller M, Polaner DM, Absalom AR, Szmuk P, Morton N, Berde C, Soriano S, Davidson AJ. Neurodevelopmental outcome at 5 years of age after general anaesthesia or awake-regional anaesthesia in infancy (GAS): an international, multicentre, randomised, controlled equivalence trial. Lancet. 2019;393(10172):664-7. https ://doi.org/10.1016/S0140-6736(18)32485-1.

36. Warner DO, Zaccariello MJ, Katusic SK, Schroeder DR, Hanson AC, Schulte PJ, Buenvenida SL, Gleich SJ, Wilder RT, Sprung J, Hu D, Voigt RG, Paule MG, Chelonis JJ, Flick RP. Neuropsychological and behavioral outcomes after exposure of young children to procedures requiring general anesthesia: the Mayo Anesthesia Safety in Kids (MASK) study. Anesthesiology. 2018;129(1):89 105. https://doi.org/10.1097/ALN.0000000000002232.

37. Hu D, Flick RP, Zaccariello MJ, Colligan RC, Katusic SK, Schroeder DR, Hanson AC, Buenvenida SL, Gleich SJ, Wilder RT, Sprung J, Warner DO. Association between exposure of young children to procedures requiring general anesthesia and learning. Anesthesiology. 2017;127(2):227-240.

38. Warner DO, Chelonis JJ, Paule MG, Frank RD, Lee M, Zaccariello MJ, Katusic SK, Schroeder DR, Hanson AC, Schulte PJ, Wilder RT, Sprung J, Flick RP. Performance on the Operant Test Battery in young children exposed to procedures requiring general anaesthesia: the MASK study. Br J Anaesth. 2019;122(4):470-9. https://doi.org/10.1016/j.bja.2018.12.020.

39. Zaccariello MJ, Frank RD, Lee M, Kirsch AC, Schroeder DR, Hanson AC, Schulte PJ, Wilder RT, Sprung J, Katusic SK, Flick RP, Warner DO. Patterns of neuropsychological changes after general anaesthesia in young children: secondary analysis of the Mayo Anesthesia Safety in Kids study. Br J Anaesth. 2019;122(5):671-81. https://doi.org/10.1016/j.bja.2019.01.022.

40. O'Leary JD, Orser BA. Neurodevelopment after general anaesthesia in infants. Lancet. 2019;393(10172):614-5. https://doi. org/10.1016/S0140-6736(18)32985-4.

41. Psaty BM, Platt R, Altman RB. Neurotoxicity of generic anesthesia agents in infants and children. JAMA. 2015;313(15):1515. https://doi.org/10.1001/jama.2015.1149.

42. Orser BA, Suresh S, Evers AS. SmartTots update regarding anesthetic neurotoxicity in the developing brain. Anesth Analg. 2018;126(4):1393-6. https://doi.org/10.1213/ANE.0000000000 002833.

43. Wilder RT, Flick RP, Sprung J, Katusic SK, Barbaresi WJ, Mickelson C, Gleich SJ, Schroeder DR, Weaver AL, Warner DO. Early exposure to anesthesia and learning disabilities in a populationbased birth cohort. Anesthesiology. 2009;110(4):796-804. https ://doi.org/10.1097/01.anes.0000344728.34332.5d.

44. Ing $\mathrm{C}$, DiMaggio $\mathrm{C}$, Whitehouse $\mathrm{A}$, Hegarty MK, Brady J, von Ungern-Sternberg BS, Davidson A, Wood AJ, Li G, Sun LS. 
Long-term differences in language and cognitive function after childhood exposure to anesthesia. Pediatrics. 2012;130(3):e476e485. https://doi.org/10.1542/peds.2011-3822.

45. Backeljauw B, Holland SK, Altaye M, Loepke AW. Cognition and brain structure following early childhood surgery with anesthesia. Pediatrics. 2015;136(1):e1-e12. https://doi.org/10.1542/ peds.2014-3526.

46. Ing C, Brambrink AM. Mayo Anesthesia Safety in Kids continued: two new studies and a potential redirection of the field. Br J Anaesth. 2019;122(6):716-9. https://doi.org/10.1016/j. bja.2019.03.011.

47. Kamat PP, Kudchadkar SR, Simon HK. Sedative and anesthetic neurotoxicity in infants and young children: not just an operating room concern. J Pediatr. 2019;204:285-90. https://doi. org/10.1016/j.jpeds.2018.08.039.

48. Devroe S, Lemiere J, Van Hese L, Gewillig M, Boshoff D, Poesen $\mathrm{K}$, Van de Velde M, Rex S. The effect of xenon-augmented sevoflurane anesthesia on intraoperative hemodynamics and early postoperative neurocognitive function in children undergoing cardiac catheterization: a randomized controlled pilot trial. Paediatr Anaesth. 2018;28(8):726-38. https://doi.org/10.1111/pan.13444.
49. Mahmoud M, Mason KP. Dexmedetomidine: review, update, and future considerations of paediatric perioperative and periprocedural applications and limitations. Br J Anaesth. 2015;115(2):171-82. https://doi.org/10.1093/bja/aev226.

50. Szmuk P, Andropoulos D, McGowan F, Brambrink A, Lee C, Lee KJ, McCann ME, Liu Y, Saynhalath R, Bong CL, Anderson BJ, Berde C, De Graaff JC, Disma N, Kurth D, Loepke A, Orser B, Sessler DI, Skowno JJ, von Ungern-Sternberg BS, Vutskits L, Davidson A. An open label pilot study of a dexmedetomidineremifentanil-caudal anesthetic for infant lower abdominal/lower extremity surgery: the T REX pilot study. Paediatr Anaesth. 2019;29(1):59-67. https://doi.org/10.1111/pan.13544.

51. Marchesini V, Disma N. Anaesthetic neuroprotection in children. Curr Opin Anaesthesiol. 2019;32(3):363-9. https://doi. org/10.1097/aco.0000000000000723.

Publisher's Note Springer Nature remains neutral with regard to jurisdictional claims in published maps and institutional affiliations. 